\title{
The effect of trialkoxysilanes on the passivation of mild steel surface modified with a zinc-phosphonate solution
}

\author{
D.O. Chugunov, A.A. Chirkunov* and Yu.I. Kuznetsov \\ A.N. Frumkin Institute of Physical Chemistry and Electrochemistry, Russian Academy of \\ Sciences, Leninsky pr. 31, 119071 Moscow, Russian Federation \\ *E-mail: chirkunov@inbox.ru
}

\begin{abstract}
The effect of trialkoxysilanes, namely, [3-(2-aminoethylamino)propyl]trimethoxysilane, vinyltrimethoxysilane (VTMS) and octyltrimethoxysilane on the protective properties of thin passivating layers formed on the surface of low carbon steel was studied. The protective layers were obtained by two-stage treatment including preliminary modification of steel surface in an aqueous solution of aminotris(methylenephosphonic acid) zinc complex followed by passivation in solutions based on a carboxylate corrosion inhibitor. Among the studied trialkoxysilanes, VTMS is the most effective as an additive to a passivating solution. The mixture of sodium oleate and VTMS has shown the highest protective properties both on airoxidized and modified steel surface, which is confirmed by the results of electrochemical measurements (potentiodynamic polarization, electrochemical impedance spectroscopy) and by accelerated corrosion tests (in a humid atmosphere and in a salt spray chamber). The criterion for assessing the protective properties of the films in polarization measurements was the difference in the pitting potentials of the passivated and air-oxidized electrodes, and in corrosion tests it was the time until the first corrosion lesions appeared. Preliminary modification of steel surface by phosphonate significantly enhanced the passivating effect of the mixture of sodium oleate and VTMS, and increased the resistance of the resulting films to the effects of humid atmosphere and chloride ions.
\end{abstract}

Keywords: corrosion inhibitors, trialkoxysilanes, aminotris(methylenephosphonic acid) zinc complex, passivity, atmospheric corrosion.

Received: June 5, 2020. Published: June 10, 2020

doi: $\underline{10.17675 / 2305-6894-2020-9-2-23}$

\section{Introduction}

In the development of methods aimed at the creation of ultra-thin layers on metals capable of preventing corrosion damage on them, an important role is played by surface passivation using corrosion inhibitors (CI) [1, 2]. A CI can form thin passivating layers on metals which do not change the appearance and size of products. For the adsorption type CI, it is important to form layers firmly adhered to the metal surface that prevent the penetration of aggressive components from the environment. Passivation of metals and alloys by organic CI is a good alternative to the use of toxic and environmentally hazardous means of anticorrosion protection, primarily chromates [2]. Various approaches can be used to increase the 
effectiveness of passivating treatment and reduce the working concentration of reagents. One of the methods may be using of synergistic mixtures in which the protective effect of the components is enhanced [2,3]. Another approach is the layered application of CI, when a pre-adsorbed layer of one CI enhances the adsorption of another, as a result of which the protective effect of the film is enhanced compared to a film of a mixed inhibitor [2,4]. To create protective films, various phosphonates that are capable of forming layers of sparingly soluble complexes and hydroxides [1] or self-assembled layers having hydrophobic properties are of interest [5]. It was previously shown [6,7] that surface modification of steel with phosphonate complexes can enhance subsequent adsorption of the composition of carboxylic acid salts with benzotriazole, providing a significant increase in the protective effect in a humid atmosphere. Initially, the modification was carried out in solutions of the zinc complex of 1-hydroxyethane-1,1-diphosphonic acid, but the aminotris(methylenephosphonic acid) complex turned out to be more effective in this role [7].

Various trialkoxysilanes (TASs), which are capable of polycondensation by the formation of siloxane bonds on the metals surface, are interesting as reagents for creating protective coatings or films on metals [8-17]. Some TASs that are stable in the aquatic environment are well adsorbed on the surface of the steel and can transfer it to a passive state in a neutral borate buffer [12].

The chemical features of TAS during interaction with the metals surface allow them to be used in conjunction with other CI. A thin siloxane layer, rigidly fixed on the surface of the metal to be protected, can contribute to $\mathrm{CI}$ retention, while its molecules maintaining a certain mobility, block defects of this layer and stabilize the passive state. The effect of the combined use of TAS with other CIs, when protected against atmospheric corrosion, can manifest itself even in very thin, actually nanoscale, layers formed from the gas phase by volatile CI [14].

Trialkoxysilanes can increase the efficiency of steel protection with salts of carboxylic acids. For example, the mutual beneficial effects of aminoethylaminopropyltrimethoxysilane (AEAPTMS) and sodium oleate (SOl) on the passivation of low carbon steel was shown [15].

In this work, we studied the effect of the addition of vinyltrimethoxysilane (VTMS), AEAPTMS, and octyltrimethoxysilane (OTMS) on the protective ability of films obtained on the surface of steel under atmospheric corrosion.

\section{Experimental}

Electrochemical and corrosion studies were carried out on low carbon steel St3 containing: C 0.14-0.22\%; Si 0.05-0.17\%; Mn 0.4-0.65\%; Ni, Cu, Cr up to 0.3\%; As: up to 0.08\%; S up to $0.05 \%$; $\mathrm{P}$ up to $0.04 \%$. As a working solution for electrochemical studies, we used a borate buffer solution ( $\mathrm{pH} 7.38 \pm 0.02)$ containing $1 \mathrm{mM} \mathrm{NaCl}(\mathrm{BBS}+1 \mathrm{mM} \mathrm{NaCl})$ with the composition: $\mathrm{H}_{3} \mathrm{BO}_{3}-11.12 \mathrm{~g} / \mathrm{L}, \mathrm{Na}_{2} \mathrm{~B}_{4} \mathrm{O}_{7}-1.9 \mathrm{~g} / \mathrm{L}, \mathrm{NaCl}-0.0585 \mathrm{~g} / \mathrm{L}$. We studied the following compounds as $\mathrm{CI}$ for atmospheric corrosion: 
Aminotris(methylenephosphonic acid) zinc complex (AMP-Zn), where AMP has the formula:

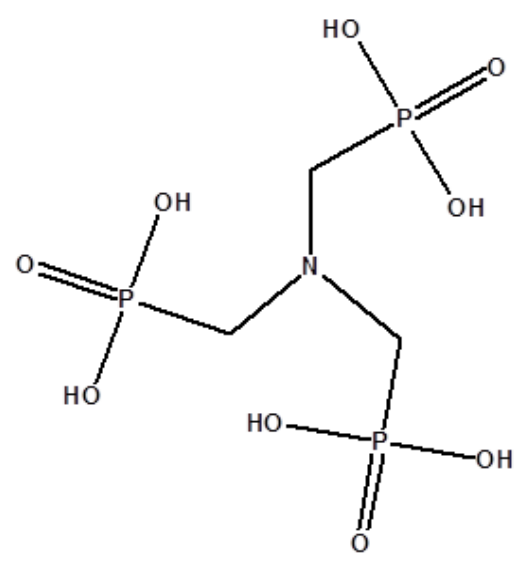

Sodium oleate (SOl), where oleic acid has the formula:

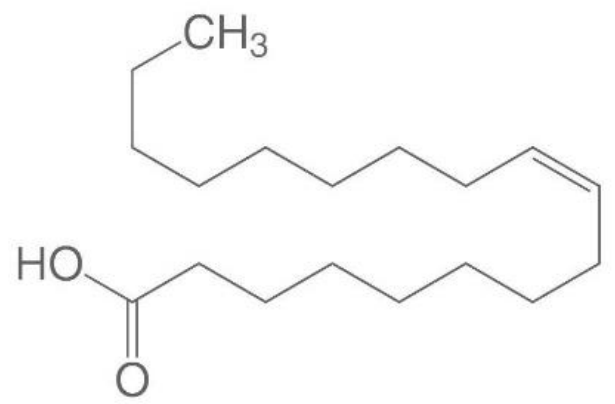

[3-(2-Aminoethylamino)propyl]trimethoxysilane (AEAPTMS):<smiles>CO[Si](C)(CCCNCCN)OC</smiles>

Vinyltrimethoxysilane (VTMS):<smiles>C=C[Si](OC)(OC)OC</smiles>

Octyltrimethoxysilane (OTMS):<smiles>CCCCCCCC</smiles>

In electrochemical studies, a cylindrical electrode was used, which was oxidized for $40 \mathrm{~min}$ in a boiling solution containing $25 \mathrm{~g} / \mathrm{L} \mathrm{NH}_{4} \mathrm{NO}_{3}, 0.4 \mathrm{~g} / \mathrm{L} \mathrm{Na}_{3} \mathrm{PO}_{4}, 1.2 \mathrm{~g} / \mathrm{L} \mathrm{NaNO}$ and $0.4 \mathrm{~g} / \mathrm{L}\left(\mathrm{NH}_{4}\right)_{2} \mathrm{~S}_{2} \mathrm{O}_{8}$, and pressed into a Teflon shell to avoid gap effects. 
The end face of the sample, $S=1.05 \mathrm{~cm}^{2}$, served as the working surface. Before the start of the experiment, the electrode was cleaned with sandpaper with different grain sizes to a mirror shine, degreased with acetone. Then, to remove the oxide film formed in air, the electrode was cathodically activated for $15 \mathrm{~min}$ in a borate buffer solution (without chlorides in it) at a potential of $E=-0.65 \mathrm{~V}$ (relative to NHE) and placed for $10 \mathrm{~min}$ in the cell with an aqueous solution of aminotris(methylenephosphonic acid) zinc complex (AMP-Zn) or a mixture of CIs. The treatment was carried out with constant stirring of the solution using a magnetic stirrer and a temperature of $80^{\circ} \mathrm{C}$. After that, the electrode was dried in air for $15 \mathrm{~min}$. Both the modified steel surface and naturally oxidized were subjected to passivation treatment to assess the contribution of the pre-modification. Passivation was carried out at $80^{\circ} \mathrm{C}$ for $10 \mathrm{~min}$ in solutions of the compositions consisting of a mixture of $4 \mathrm{mM}$ $\mathrm{SOl}+4 \mathrm{mM}$ VTMS, $4 \mathrm{mM} \mathrm{SOl+4} \mathrm{mM}$ AEAPTMS, $4 \mathrm{mM} \mathrm{SOl}+4 \mathrm{mM}$ OTMS, as well as these chemical compounds separately.

The electrochemical estimation of the protective properties of nano-coatings previously formed in aqueous solutions at St3 was carried out in a two-chamber electrochemical cell on a disk electrode using an IPC-ProMF potentiostat. The saturated silver chloride electrode served as the reference electrode, and platinum served as the supporting electrode. The passivated electrode was screwed onto the holder and lowered into the electrochemical cell so that the distance from the working surface to the tip of the Luggin capillary did not exceed $1 \mathrm{~mm}$. Anodic polarization began immediately after immersion of the electrode in a borate buffer solution. The potentiodynamic sweep rate was $v=0.2 \mathrm{mV} / \mathrm{s}$. All tests were performed at room temperature and natural aeration. The protective properties of the coatings were evaluated by the value $\Delta E=E_{\mathrm{pt}}^{\mathrm{in}}-E_{\mathrm{pt}}^{0}$, where the upper indices refer to a solution containing $\mathrm{CI}$ and without it, respectively.

The electrochemical impedance spectra (EIS) were measured using an Autolab PGSTAT302 potentiostat with a FRA32M module in the frequency range $f$ from $10 \mathrm{kHz}$ to $0.1 \mathrm{~Hz}$ with an alternating voltage amplitude of $10 \mathrm{mV}$. The borate buffer at $\mathrm{pH} 7.4$ served as the background solution. Working electrodes were prepared similarly to electrodes for polarization measurements. The results were processed using the NOVA program.

For the calculations, the following equivalent circuit was used:

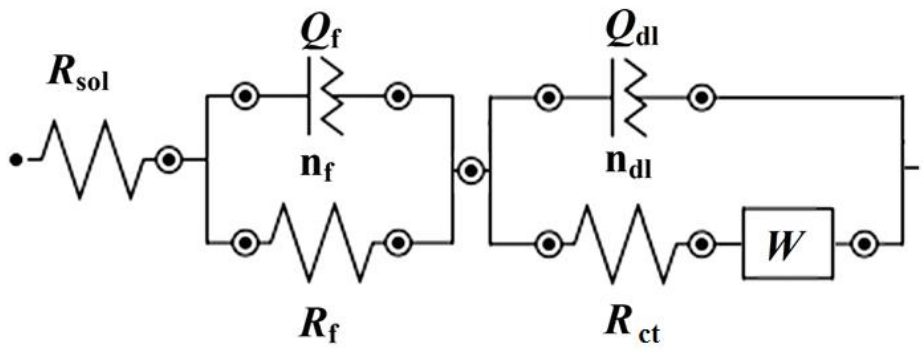

Where $R_{\text {sol }}$ is the resistance of the solution; $Q_{\mathrm{f}}$ and $n_{\mathrm{f}}$ are the parameters of the constant phase element ( $C P E)$ describing the capacity of the surface film; $R_{\mathrm{f}}$ is the film resistance; 
$Q_{\mathrm{dl}}$ and $n_{\mathrm{dl}}$ parameters of a $C P E$ describing the capacity of the double electric layer; $R_{\mathrm{p}}$ is the polarization resistance; $W$ is the Warburg impedance simulating the diffusion process.

Corrosion tests were carried out on steel plates $30 \times 50 \mathrm{~mm}$ in size, which were prepared similarly to electrodes in electrochemical experiments. They were tested in a humid atmosphere during periodic (daily) moisture condensation on $\mathrm{St} 3$ steel samples, which were prepared in the same way as they were done in electrochemical measurements. Then, samples from St3 were placed in a desiccator where water was previously poured with a temperature of $t=50^{\circ} \mathrm{C}$. Hot water was changed once a day. Abundant condensation of moisture occurred during cooling.

To enhance the corrosive effect of an aggressive atmosphere, some samples were immersed in a $0.1 \% \mathrm{NaCl}$ solution for $5 \mathrm{~s}$ before being placed in a cell. Upon drying of such a solution, aggressive chlorides in the amount of $21 \mathrm{mg} / \mathrm{m}^{2}$ settled on the samples. The effectiveness of the passivating treatment was judged by the time until the first corrosion lesions $\left(\tau_{\mathrm{cor}}, \mathrm{h}\right)$.

\section{Results and Discussion}

AEAPTMS is highly soluble in water, forming stable solutions for a long time, and it is able to transfer steel to a passive state, but slightly inhibits local depassivation $[12,15]$. Its protective effect can be enhanced by combined use with higher carboxylated CIs, in particular with sodium oleylsarcosinate, as shown by the example of the aluminum alloy AMg6 [16].

The results obtained during polarization measurements on mild steel St3 in a borate buffer solution containing $1 \mathrm{mmol} / \mathrm{L} \mathrm{NaCl}$ (Figure 1) show that AEAPTMS films formed on the steel surface at $t=80^{\circ} \mathrm{C}$ allow increasing $\Delta E$, although the protective effect is low. However, in a mixture with SOl, AEAPTMS forms a coating characterized by a high value of $\Delta E=0.96 \mathrm{~V}$. This is far superior to the criterion $(\Delta E=0.40 \mathrm{~V})$, indicating a high protective ability of nanosized coatings on steel when evaluated according to the results of polarization measurements $[6,7]$. The film formed in the AEAPTMS+SOl solution on the modified AMP $-\mathrm{Zn}$ steel surface is also characterized by a high $\Delta E=1.0 \mathrm{~V}$. Composition SOl+OTMS (Figure 2) forms layers that slightly weaken the local depassivation of steel $(\Delta E=0.89 \mathrm{~V})$ compared to SOl+AEAPTMS and its protective effect is weakened by passivation of the modified surface $(\triangle E=0.67 \mathrm{~V})$. This is probably due to the rapid hydrolysis of OTMS in solution and spatial difficulties in the formation of the protective layer, especially during the passivation of a more inhomogeneous modified surface.

When a passivating film is formed on the naturally oxidized steel surface, the addition of VTMS to SOl provides $\Delta E=0.605 \mathrm{~V}$ (Figure 3). The application of this composition after treatment in a solution of AMP-Zn increases $\Delta E$ to $0.740 \mathrm{~V}$, which confirms the positive effect of preliminary surface modification. In comparison with the previously considered treatment method of steel, including surface modification in a phosphonate solution and subsequent passivation with the composition of SOl and BTA, the replacement of BTA by VTMS increases $\Delta E$. 


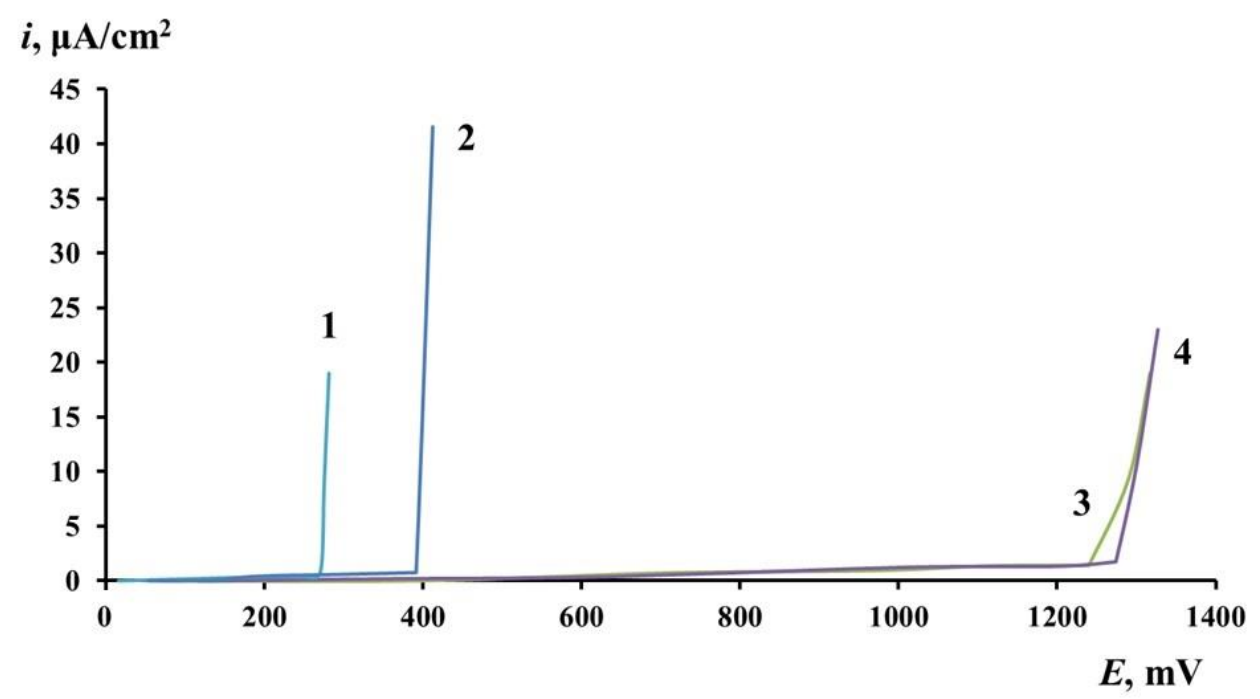

Figure 1. Anode polarization curves of St3 steel in a borate buffer containing $0.001 \mathrm{M} \mathrm{NaCl}$. 1-without treatment; 2-8 mM AEAPTMS; 3-4 mM SOl+4 mM AEAPTMS; 4-8 mM AMP-Zn/4 mM SOl+4 mM AEAPTMS.

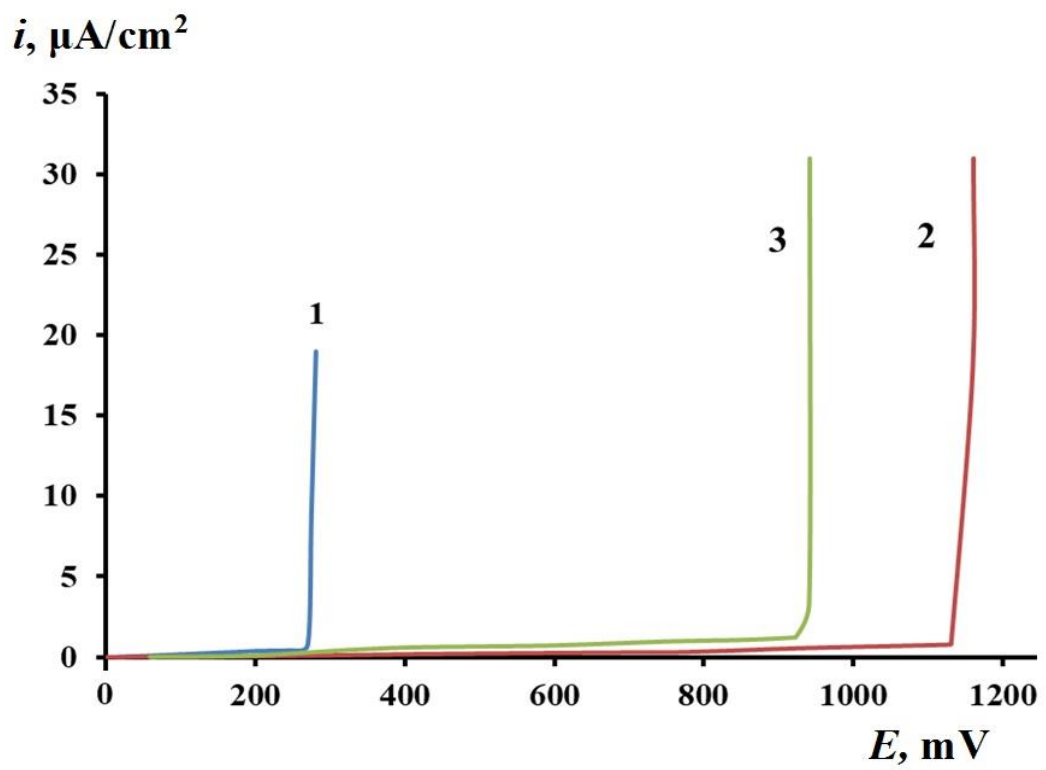

Figure 2. Anode polarization curves of St3 steel in a borate buffer containing $0.001 \mathrm{M} \mathrm{NaCl}$. 1-without treatment; 2-4 mM SOl+4 mM OTMS; 3-8 mM AMP-Zn/4 mM SOl+4 mM OTMS.

A more noticeable contribution of VTMS to the shift of the depassivation potential is observed when it is used together with AMP-Zn before passivation with the SOl+BTA composition: $\Delta E=0.906 \mathrm{~V}$. 


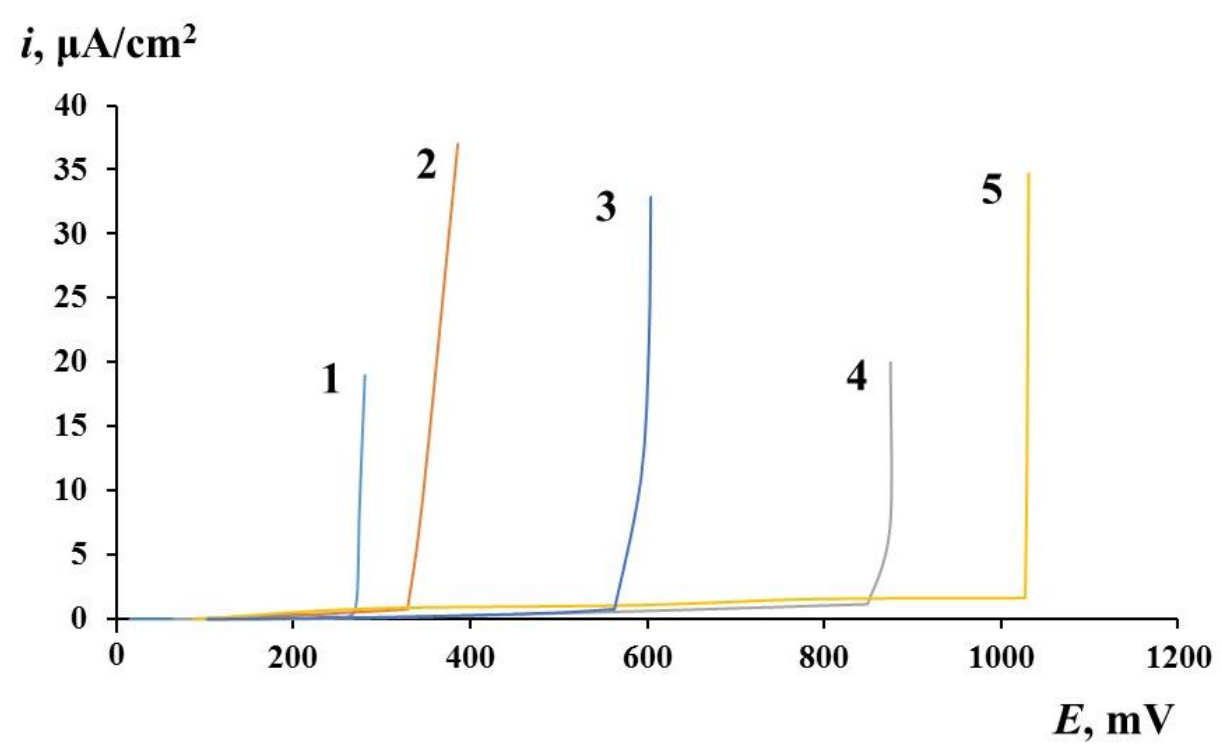

Figure 3. Anode polarization curves of St3 steel in a borate buffer containing $0.001 \mathrm{M} \mathrm{NaCl}$. 1-without treatment; 2-8 mM AMP-Zn; 3-8 mM VTMS; 4-4 mM SOl+4 mM VTMS; 5-8 mM AMP-Zn/4 mM SOl+4 mM VTMS.

Given the results of electrochemical measurements, it can be assumed that thin films containing AEAPTMS, OTMS or VTMS can shows a high degree of steel protection in a humid atmosphere and during corrosion tests. Indeed, under conditions of periodic moisture condensation, VTMS also shows a positive effect both when the steel surface is modified and when it is passivated (Table 1). The first signs of corrosion on treated samples appear after more than 1500 hours, i.e. more than 62 days, tests. As in previous studies, the possibility of using $\Delta E$ as a criterion for the resistance of films is confirmed: the layers characterized by $\Delta E>0.40 \mathrm{~V}$ are most effective.

These tests prove that in rather harsh conditions of a humid atmosphere with daily condensation of moisture on the steel surface, the most effective way to protect it, consisting of two stages. First, the steel is treated with a solution of $8 \mathrm{mmol} / \mathrm{L} \mathrm{AMP}-\mathrm{Zn}$ to modify its surface, followed by passivation in an aqueous solution of a mixture of SOl with VTMS. This ensures that the first signs of corrosion are prevented for more than 2 months $\left(\tau_{\text {cor }}=1584 \mathrm{~h}\right)$.

In order to reduce the time spent on testing, as well as to assess the resistance of films to aggressive anions, accelerated tests were conducted under conditions of moisture condensation with preliminary exposure of passivated samples in a solution contains $0.1 \%$ $\mathrm{NaCl}$ for $5 \mathrm{~s}$ and drying them in air. During moisture condensation on samples, $\mathrm{NaCl}$ dissolves in the moisture film, increasing its aggressive effect on steel. In this case, the first corrosion damage appears much faster than in similar experiments without first applying chlorides to steel (Table 2). The protective effect of steel treatment with a solution of $8 \mathrm{mmol} / \mathrm{L}$ AMP-Zn sharply decreases: $\tau_{\text {cor }}$ decreases to 3 hours, which indirectly indicates the heterogeneity of the modified surface and the presence of defects on it. 
Table 1. Test results for samples of St3 steel with various treatments under conditions of periodic water condensation.

\begin{tabular}{ccc}
\hline $\begin{array}{c}\text { The composition of the solutions and the } \\
\text { sequence of steel treatment before testing }\end{array}$ & $\boldsymbol{\Delta} \boldsymbol{E}, \mathbf{V}$ & $\boldsymbol{\tau}_{\text {cor }}, \mathbf{h}$ \\
\hline Without treatment & - & $<12$ \\
$8 \mathrm{mM}$ AMP-Zn & 0.053 & 120 \\
$8 \mathrm{mM}$ AMP-Zn+4 mM VTMS & 0.29 & 312 \\
$4 \mathrm{mM}$ SOl+4 mM VTMS & 0.61 & - \\
$8 \mathrm{mM}$ AMP-Zn/4 mM SOl+4 mM VTMS & 0.74 & 1584 \\
\hline
\end{tabular}

Under these conditions, the VTMS film provides protection only for 36 hours (Table 2), while replacing half of the VTMS with SOl increases $\tau_{\text {cor }}$ up to 480 hours. This indicates the defectiveness of the VTMS film and the need for an inhibitor capable of passivating steel under aggressive conditions of exposure to $\mathrm{NaCl}$.

Table 2. The results of corrosion tests in a humid atmosphere of the samples of steel St 3 passivated at $80^{\circ} \mathrm{C}$ and exposed in $0.1 \% \mathrm{NaCl}$.

\begin{tabular}{cc}
\hline The composition of the solutions and the sequence of steel treatment before testing & $\boldsymbol{\tau}_{\text {cor, }} \mathbf{h}$ \\
\hline Without treatment & $\sim 1$ \\
$8 \mathrm{mM}$ AMP-Zn & 3 \\
$4 \mathrm{mM}$ SOl+4 mM AEAPTMS & 24 \\
$8 \mathrm{mM} \mathrm{AMP-Zn/4} \mathrm{mM} \mathrm{SOl+4} \mathrm{mM} \mathrm{AEAPTMS}$ & 96 \\
$8 \mathrm{mM}$ VTMS & 36 \\
$4 \mathrm{mM}$ SOl+4 mM VTMS & 480 \\
$8 \mathrm{mM}$ AMP-Zn/4 mM SOl+4 mM VTMS & 840 \\
\hline
\end{tabular}

The maximum effect among the studied compositions is provided by the passivating SOl solution with VTMS in the treatment of AMP-Zn-modified steel surface $-\tau_{\text {cor }}$ in this case reaches 840 hours.

Although $\tau_{\text {cor }}$ values was relatively close during normal moisture condensation, the difference in the behavior of the samples passivated by SOl+VTMS appears itself in humid atmosphere when exposed to chloride ions. This is probably due to a temporary factor: in the absence of $\mathrm{NaCl}$, the protective layers experience less load, but are gradually washed off and destroyed by condensing moisture. In this case, the thickness of the layers and the strength of their bonds play an important role. Under the influence of chloride ions, the perfection of the film, i.e. the absence of defects in it and the packing density of the layers, which can be facilitated by the possibility of polycondensation of VTMS on the surface with 
the formation of a rigid structure and subsequent adsorption of an $\mathrm{SOl}$ on it, which covering defects and forming an external moving film. The thickness of the films obtained on steel after modification in a solution of $8 \mathrm{mM}$ AMP-Zn and subsequent passivation with a composition of $4 \mathrm{mM} \mathrm{SOl}+4 \mathrm{mM}$ VTMS was determined by the ellipsometric method and amounted to $58 \mathrm{~nm}$. When the sample was washed with distilled water for $1 \mathrm{~min}$, the film thickness decreased to $20 \mathrm{~nm}$, but this did not change the value of $E_{\mathrm{pt}}$, although in tests under conditions of periodic moisture condensation, the film thickness can play an important role.

Coatings based on AEAPTMS, as can be seen from the data presented (Table 2), despite higher $\Delta E$ values, have a lower protective effect compared to films based on VTMS. Such a discrepancy in the results of corrosion and electrochemical tests may be due to the structure of the films. TASs are capable of polycondensation in aqueous solutions or on the surface of metals $[14,17]$ while simultaneously forming $\mathrm{Si}-\mathrm{O}-\mathrm{Me}$ bonds with their surface, thereby forming dense films. However, in the case of AEAPTMS, its stability in aqueous solutions can impede rapid polycondensation, while VTMS rapidly hydrolyzes upon contact with water and begins to condense already in solution. The latter remains relatively stable only at elevated temperatures during the processing period, while white flakes are detected after use in the passivating solution. An additional obstacle to AEAPTMS may be the possibility of its interaction with ARS due to the presence of amino groups in the molecule.

An additional characterization of the modifying and passivating layers was carried out using EIS, including in comparison with previously studied films based on the compositions of AMP-Zn with sodium nitrite and SOl with BTA [7]. The results are presented in Figures 4 and 5. The equivalent electrical circuit (EEC) presented above includes 2 consecutive $R-$ $C P E$ circuits and a Warburg element.

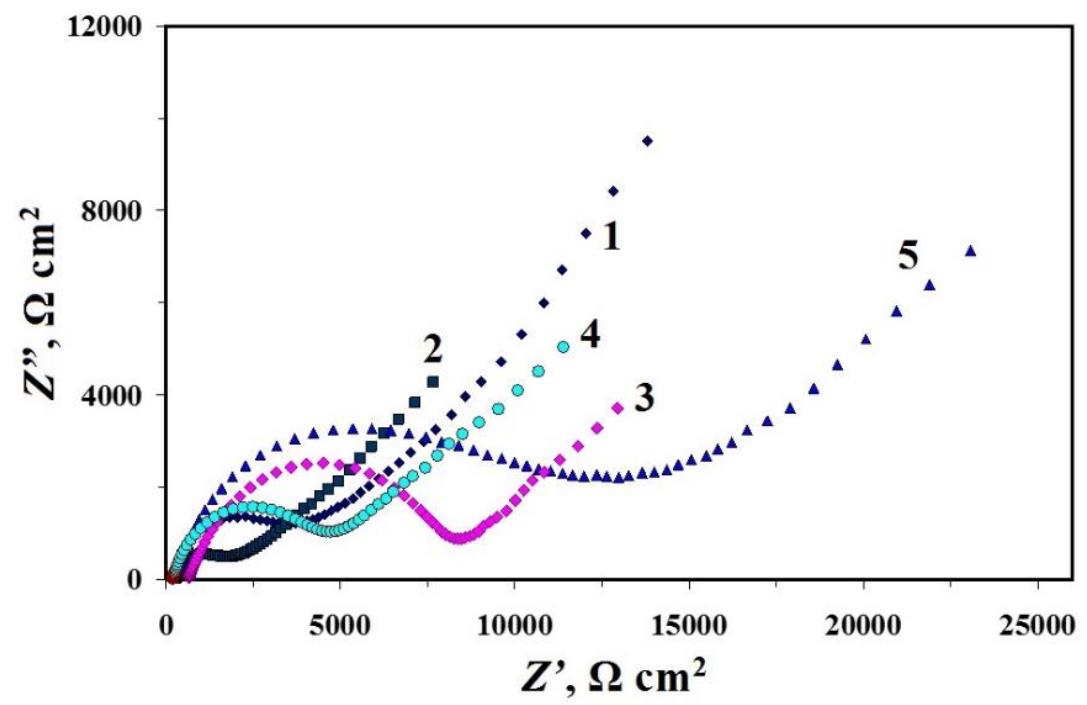

Figure 4. Nyquist diagrams obtained on St3 steel with various surface treatments: 1 - without treatment; 2 - $8 \mathrm{mM}$ AMP-Zn; 3 - $8 \mathrm{mM}$ AMP-Zn+8 $\mathrm{mM} \mathrm{NaNO}_{2} ; 4-4 \mathrm{mM} \mathrm{SOl}+4 \mathrm{mM}$ BTA; 5 - $4 \mathrm{mM} \mathrm{SOl+4} \mathrm{mM} \mathrm{VTMS.}$ 


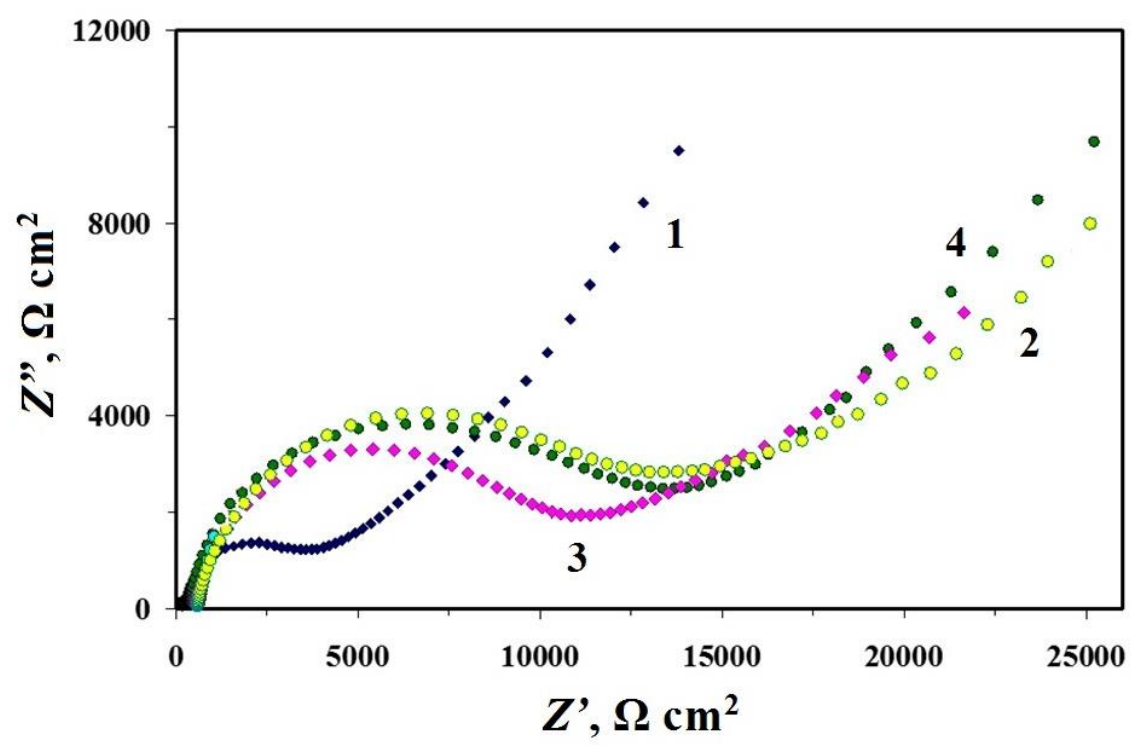

Figure 5. Nyquist diagrams obtained on St3 steel with various surface treatments: 1 - without treatment; 2 - $8 \mathrm{mM}$ AMP-Zn/4 mM SOl+4 mM BTA; 3 - $8 \mathrm{mM}$ AMP-Zn+8 mM $\mathrm{NaNO}_{2} / 4$ mM SOl+4 mM BTA; 4 - 8 mM AMP-Zn/4 mM SOl+4 mM VTMS.

Using $C P E$ instead of a real capacitance is due to the inhomogeneity of the electrode surface and the non-ideal behavior of the surface films associated with inhomogeneous conductivity inside the layers. The Warburg element is used to describe diffusion-controlled processes, including the transport of reagents from the bulk of the solution to the surface of the electrode or the transport of soluble products into the solution. The calculation results of the spectra obtained for this EES are presented in Table 3.

Table 3. Parameters of EEC for mild steel with various films.

\begin{tabular}{|c|c|c|c|c|c|c|c|c|}
\hline \multirow[b]{2}{*}{ Parameter } & \multicolumn{8}{|c|}{ Method of treatment } \\
\hline & $\begin{array}{l}\text { Without } \\
\text { treatment }\end{array}$ & 8 AMP-Zn & $\begin{array}{l}8 \mathrm{AMP}-\mathrm{Zn} \\
+8 \mathrm{NaNO}_{2}\end{array}$ & $\begin{array}{c}4 \text { SOI + } \\
4 \text { BTA }\end{array}$ & $\begin{array}{c}4 \text { SOI + } \\
4 \text { VTMS }\end{array}$ & $\begin{array}{l}\text { 8 AMP- } \\
\text { Zn / 4 SOI } \\
+4 \text { BTA }\end{array}$ & $\begin{array}{l}8 \text { AMP- } \\
\text { Zn / } 4 \text { SOI } \\
+4 \text { VTMS }\end{array}$ & $\begin{array}{c}8 \mathrm{AMP}-\mathrm{Zn} \\
+8 \mathrm{NaNO}_{2} / \\
4 \mathrm{SOI}+ \\
4 \mathrm{BTA}\end{array}$ \\
\hline$R_{\mathrm{s}}$ & 282.6 & 290.5 & 230.1 & 280.3 & 269.8 & 236.1 & 270.3 & 270.2 \\
\hline$R_{\mathrm{f}}\left(\Omega \mathrm{cm}^{2}\right)$ & 2654.4 & 951.6 & 2446.6 & 759.5 & 7283.8 & 7619.9 & 9577.4 & 5943.7 \\
\hline$Q_{\mathrm{f}}\left(\mathrm{S} \mathrm{s}^{n} / \mathrm{cm}^{2}\right)$ & $1.02 \cdot 10^{-4}$ & $1.57 \cdot 10^{-6}$ & $4.20 \cdot 10^{-5}$ & $7.38 \cdot 10^{-7}$ & $2.98 \cdot 10^{-6}$ & $1.25 \cdot 10^{-6}$ & $8.71 \cdot 10^{-7}$ & $1.07 \cdot 10^{-4}$ \\
\hline$n_{\mathrm{f}}$ & 0.5325 & 0.8659 & 0.5988 & 0.8701 & 0.5627 & 0.8073 & 0.9257 & 0.5648 \\
\hline$R_{\mathrm{p}}\left(\Omega \mathrm{cm}^{2}\right)$ & 2320.5 & 5275.2 & 7432.4 & 5316.4 & 6864.1 & 7934.6 & 9470.8 & 8455.1 \\
\hline$Q_{\mathrm{dl}}\left(\mathrm{S} \mathrm{s}^{n} / \mathrm{cm}^{2}\right)$ & $1.77 \cdot 10^{-6}$ & $2.60 \cdot 10^{-4}$ & $3.37 \cdot 10^{-6}$ & $3.88 \cdot 10^{-6}$ & $3.08 \cdot 10^{-6}$ & $3.81 \cdot 10^{-6}$ & $8.34 \cdot 10^{-6}$ & $1.15 \cdot 10^{-6}$ \\
\hline$n_{\mathrm{dl}}$ & 0.9281 & 0.3273 & 0.7542 & 0.7882 & 0.8216 & 0.6644 & 0.6666 & 0.8079 \\
\hline$W\left(S \mathrm{~s}^{1 / 2} / \mathrm{cm}^{2}\right)$ & $2.90 \cdot 10^{-4}$ & $1.40 \cdot 10^{-4}$ & $7.84 \cdot 10^{-4}$ & $3.93 \cdot 10^{-4}$ & $3.87 \cdot 10^{-4}$ & $3.06 \cdot 10^{-4}$ & $2.85 \cdot 10^{-4}$ & $4.69 \cdot 10^{-4}$ \\
\hline
\end{tabular}


From the data obtained, it can be seen that after treatment of steel in the AMP-Zn solution, the film resistance decreases compared to the naturally oxidized electrode, however, the charge transfer resistance increases significantly. It should also be noted that, compared with the background electrode, $Q_{\mathrm{dl}}$, which characterizes the capacitance of the double electric layer, increases significantly. In this case, the parameter $n_{\mathrm{dl}}$ is low, while on the background sample $n_{\mathrm{dl}}$ is close to 1 . This indicates a high heterogeneity of the structure of the protective film. Nevertheless, an increase in $R_{\mathrm{ct}}$ indicates the presence of protective properties for this film, which is consistent with previously obtained results of electrochemical measurements and corrosion tests in a humid atmosphere. The CPE values characterizing surface films do not allow a clear comparative analysis of the films due to their different nature.

Treatment of steel in a solution containing AMP- $\mathrm{Zn}$ and the addition of sodium nitrite gives a film resistance value close to that of a natural oxide film and provides a significant increase in $R_{\text {ct. }}$. The value of $Q_{\text {dl }}$ in this case is of the same order as for the background electrode, and $n_{\mathrm{dl}}$ is significantly increased in comparison with the electrode treated with AMP-Zn. Obviously, the positive effect of the oxidizing additive is associated with the formation of a more homogeneous surface film.

As a result of the formation of SOl+BTA film on the steel surface, the $Q_{\mathrm{f}}$ value decreases, but the film resistance also decreases, apparently due to its high electrical conductivity. In this case, the values of $R_{\mathrm{ct}}$ are comparable to the film formed by the AMP$\mathrm{Zn}$ and are significantly inferior to the AMP-Zn-nitrite films. This apparent discrepancy with the results of electrochemical and corrosion tests is due to the fact that, in the absence of depassivation anions, oxide films and layers of complex compounds can have good barrier properties, however, with an increase in the aggressiveness of solutions or an increase in the duration of exposure to the medium (as occurs during corrosion tests), defects such films become centers of corrosion. At the same time, carboxylate films blocks these defects, and also, due to strong adsorption and relative mobility of the outer layers under conditions of multimolecular adsorption, they can resist the effects of corrosive reagents for a long time.

Replacing BTA with VTMS in a passivating solution promotes an increase in $R_{\mathrm{f}}$ and $R_{\mathrm{ct}}$, i.e. enhances the protective and barrier properties of a passivating film. When passivating films are formed on a modified surface, their behavior in some cases changes significantly. For example, SOl+BTA film characterized by a small $R_{\mathrm{f}}$ value, after application of the AMP $-\mathrm{Zn}$ to the sublayer, contributes to a significant increase in $R_{\mathrm{f}}$, which significantly exceeds the sum of the values characteristic of individual layers.

The value of $R_{\mathrm{ct}}$ also increases markedly. Obviously, this is due to a stronger adsorption of SOl precisely on the modified surface, due to which the barrier properties of the film are enhanced. A similar picture is observed during the adsorption of the SOl+VTMS composition, while on the modified steel surface it also surpasses SOl+BTA, as well as on the oxidized one. Although the $n_{\mathrm{dl}}$ values indicate surface heterogeneity, its degree decreases in comparison with the modifying layer itself due to CI adsorption. 
Under the adsorption of the SOl+BTA layer on the surface modified in the presence of an oxidizing agent, the film resistance decreases somewhat, probably due to a decrease in its thickness. However, the value of $R_{\mathrm{ct}}$ increases, probably due to the adsorption of the inhibitor on a more homogeneous surface, as evidenced by the parameters $C P E_{\mathrm{dl}}$, due to which the film is less defective at a smaller thickness. At the same time, for a passivating composition containing VTMS, the heterogeneity factor may play a lesser role, since the silane forms its own spatial network.

\section{Conclusions}

1. Among the studied trialkoxysilanes (aminoethylaminopropyl-trimethoxysilane, vinyltrimethoxysilane, octyltrimethoxysilane), VTMS is most effective as an additive to a passivating solution, demonstrating an increase in the protective effect, both during electrochemical and corrosion tests. This is apparently due to the polycondensation of VTMS on the steel surface, forming a rigid network of siloxane structure, which includes SOl anions. Such a protective film is less defective and provides stable passivation of steel in atmospheric conditions. The weak effect of AEAPTMS additives is due to its stability and good solubility in water, which complicate its rapid polycondensation on the steel surface, especially in the presence of SOl. In the case of OTMS, the low protective effect, on the contrary, is due to too fast hydrolysis and polycondensation in solution, as well as spatial difficulties in the formation of surface layers.

2. The combined use of SOl and VTMS allows one to increase the protective effect of passivating films formed on the mild steel surface, which is further enhanced on a surface pre-modified with phosphonate. The surface treatment of steel in an AMP-Zn solution increases the resistance of the SOl+VTMS films obtained on it to the corrosive effects of chloride ions, which is confirmed by an increase of $\Delta E$ in polarization measurements, as well as by corrosion testing of stored samples previously held in a $0.1 \% \mathrm{NaCl}$ solution.

3. The EIS results indicate an increase in the degree of heterogeneity of the steel surface after its modification in the AMP-Zn solution, and also confirm the highest resistance of the passivating films formed by the SOI+VTMS composition on the modified surface.

\section{References}

1. Yu.I. Kuznetsov, Organic Inhibitors of Corrosion of Metals, Plenum Press, New York and London, 1996, 283.

2. Yu.I. Kuznetsov, Organic corrosion inhibitors: where are we now? A review. Part II. Passivation and the role of chemical structure of carboxylates, Int. J. Corros. Scale Inhib., 2016, 5, no. 4, 282-318. doi: 10.17675/2305-6894-2016-5-4-1

3. U. Rammelt, S. Koehler and G. Reinhard, Synergistic effect of benzoate and benzotriazole on passivation of mild steel, Corros. Sci., 2008, 50, 1659-1663. doi: $\underline{10.1016 / j . c o r s c i .2008 .02 .016}$ 
4. Yu.I. Kuznetsov, N.P. Andreeva and M.O. Agafonkina, On intensification of iron passivation by benzotriazole in aqueous solutions, Prot. Met. Phys. Chem. Surf., 2010, 46, no. 5, 603-608. doi: 10.1134/S2070205110050187

5. T. Abohalkuma, F. Shawish and J. Telegdi, Phosphonic acid derivatives used in self assembled layers against metal corrosion, Int. J. Corros. Scale Inhib., 2014, 3, no. 3, 151-159. doi: 10.17675/2305-6894-2014-3-3-151-159

6. Yu.I. Kuznetsov, A.A. Chirkunov and I.A. Filippov, The effect of steel modifying with zinc oxyethylidenediphosphonate on its passivation in solutions of certain inhibitors, Russ. J. Electrochem., 2013, 49, no. 12, 1107-1114. doi: 10.1134/S1023193513120045

7. A.A. Chirkunov, D.O. Chugunov, G.V. Red'kina and Yu.I. Kuznetsov, The Influence of Steel Surface Modifying with Zinc Complexes of Phosphonic Acids on the Efficiency of Its Passivation by Organic Inhibitors, Russ. J. Electrochem., 2019, 55, no. 12, 115121. doi: 10.1134/S1023193519010026

8. K. Aramaki, The healing effect of polymer films containing a non-chromate inhibitor on iron corrosion at scratched surfaces, Corros. Sci., 2000, 42, 1975-1991. doi: 10.1016/S0010-938X(00)00031-7

9. A. Frignani, F.Zucchi, G. Trabanelli and V. Grassi, Protective action towards aluminium corrosion by silanes with a long aliphatic chain, Corros. Sci., 2006, 48, $2258-$ 2273. doi: $10.1016 /$ j.corsci.2005.06.018

10. V.V. Men'shikov, A.A. Kalinkina, D.V. Mazurova, E.F. Akimova and T.A. Vagramyan, Primenenie vodnykh rastvorov silanov dlya podgotovki poverkhnosti metalla pered naneseniem lakokrasochnykh pokrytii (obzor) (The use of aqueous solutions of silanes to prepare the metal surface before applying paint coatings (A review)), Korroz.: mater., zashch. (Corrosion: Materials, Protection), 2010, no. 4, 30-36 (in Russian).

11. H. Fan, S. Li, Z. Zhao, H. Wang, Z. Shi and L. Zhang, Inhibition of brass corrosion in sodium chloride solutions by self-assembled silane films, Corros. Sci., 2011, 53, 4273 4281. doi: $10.1016 / j . c o r s c i .2011 .08 .039$

12. A.A. Chirkunov, A.M. Semiletov, Yu.I. Kuznetsov and N.P. Andreeva, Passivatsiya stali vodnymi rastvorami trialkoksisilanov (Passivation of steel by aqueous solutions of trialkoxysilanes), Korroz.: mater., zashch. (Corrosion: Materials, Protection), 2013, no. 11, 27-34 (in Russian).

13. S. Al-Saadi and R.K. Singh Raman, A long aliphatic chain functional silane for corrosion and microbial corrosion resistance of steel, Prog. Org. Coat., 2019, 127, $27-$ 36. doi: 10.1016/i.porgcoat.2018.10.024

14. A.V. Agafonkin, Yu.I. Kuznetsov and N.P. Andreeva, Formirovanie zashchitnykh nanosloev na metallakh $\mathrm{N}$-benzilbenzilideniminom i (3-aminopropil)-trietoksisilanom iz gazovoi fazy (The formation of protective nanolayers on metals with $\mathrm{N}$ benzylbenzylideneimine and (3-aminopropyl)-triethoxysilane from the gas phase), Korroz.: mater., zashch. (Corrosion: Materials, Protection), 2010, no. 8, 24-30 (in Russian). 
15. A.M. Semiletov, A.A. Chirkunov, Yu.I. Kuznetsov and N.P. Andreeva, Improving steel passivation with aqueous solutions of [3-(2-Aminoethylamino)propyl]trimethoxysilane, Russ. J. Phys. Chem. A, 2015, 89, no. 12, 1915-1922. doi: $10.1134 / \mathrm{S} 0036024415120262$

16. A.M. Semiletov, Yu.I. Kuznetsov and A.A. Chirkunov, Ingibirovanie atmosfernoi korrozii alyuminievogo splava AMg6 trialkoksisilanami i ikh kompoziciyami s karboksilatami (Inhibition of atmospheric corrosion of AMg6 aluminum alloy by trialkoxysilanes and their compositions with carboxylates), Korroz.: mater., zashch. (Corrosion: Materials, Protection), 2016, no. 6, 29-36 (in Russian).

17. M.A. Petrunin, N.A. Gladkikh, M.A. Maleeva, L.B. Maksaeva and T.A. Yurasova, The use of organosilanes to inhibit metal corrosion. A review, Int. J. Corros. Scale Inhib., 2019, 8, no. 4, 882-907. doi: 10.17675/2305-6894-2019-8-4-6

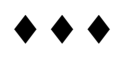

